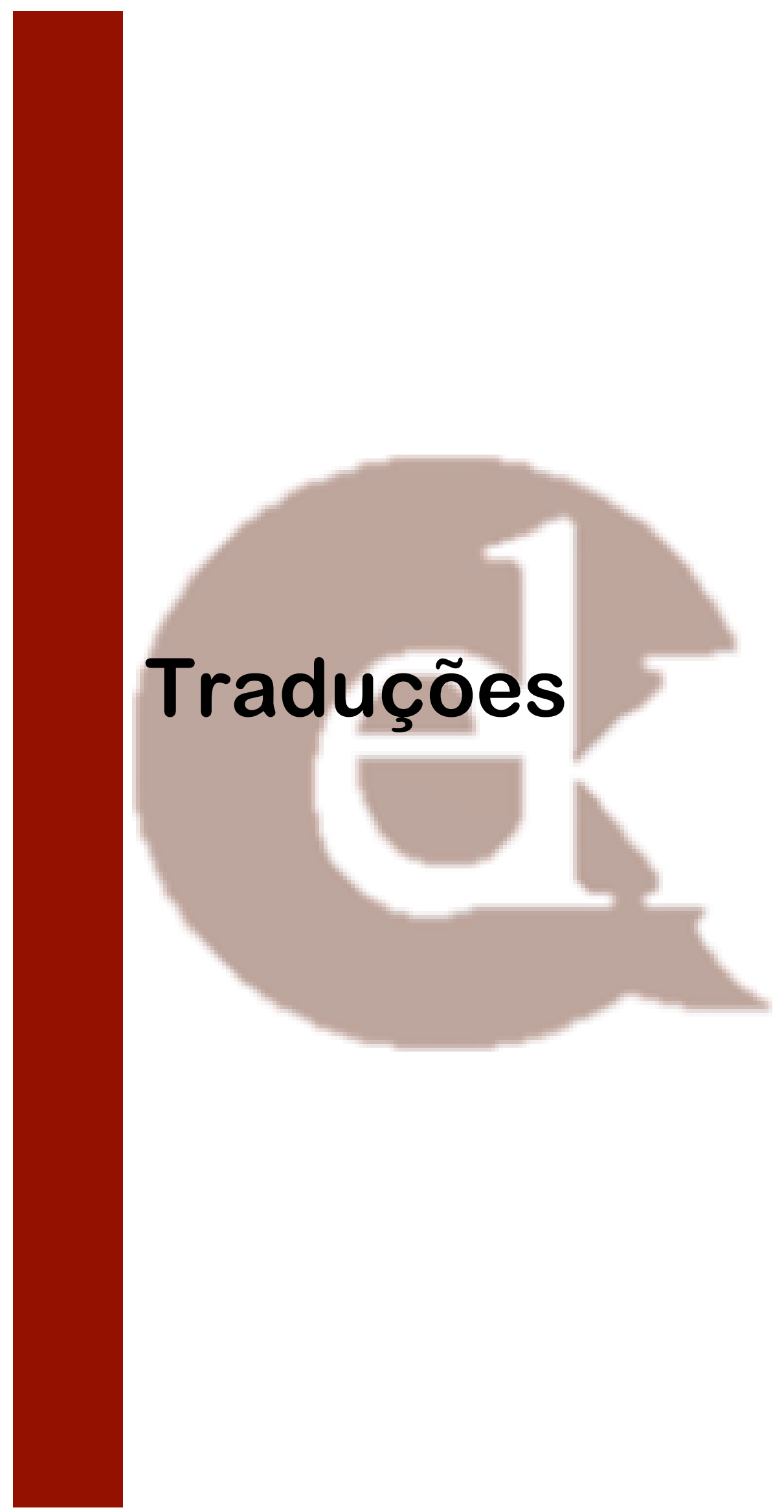




\section{A disputa de Davos entre Ernst Cassirer e Martin Heidegger}

Davoser Disputation zwischen Ernst Cassirer und Martin Heidegger

DOI: 10.12957/ek.2020.51767

Tradução da Disputa (anexo IV):

Dr. Adriano Ricardo Mergulhão1

adrianomergulhao@yahoo.com.br

Universidade Federal de São Carlos (UFSCar)

Tradução do anexo III, revisão das traduções, apresentação e notas:

Dra. Deborah Moreira Guimarães2

deborahmoreiraguimaraes@gmail.com

Universidade Federal de São Paulo (UNIFESP)

1 Doutor em filosofia pela Universidade Federal de São Carlos (UFSCAR, 2018). Foi bolsista CAPES/PDSE, atuando como pesquisador convidado na Humboldt-Universität zu Berlin (HU Berlin, 2017). Mestre em Filosofia pela Faculdade de São Bento/SP (FSB, 2011). Graduado em Filosofia pela Universidade Estadual Paulista Júlio de Mesquita Filho (UNESP, 2006). Professor de filosofia da Rede Estadual de Ensino de São Paulo.

2 É mestre e doutora em Filosofia pela UNIFESP. Pesquisa temas relacionados à fenomenologia e à hermenêutica. 


\section{APRESENTAÇÃO}

Apresentamos a tradução para a língua portuguesa dos apêndices III e IV do terceiro tomo da edição das obras completas de Martin Heidegger pela editora Vittorio Klostermann (Gesamtausgabe 3): Kant e o problema da metafísica (Kant und das Problem der Metaphysik), de 1929. Considerada uma das maiores interpretações da obra de Kant realizadas no século XX, o Kant-Buch, tal como também é conhecido, abrange uma seção de apêndices, ou anexos, que contém seis textos complementares ao conteúdo propriamente dito da obra. Realizamos, portanto, as traduções do anexo III, "Conferências de Davos: a Crítica da razão pura de Kant e a tarefa de uma fundamentação da metafísica", e do anexo IV, "Disputa de Davos entre Ernst Cassirer e Martin Heidegger”, debate ocorrido em 26 de março de 1929. A versão aqui traduzida teve como base a transcrição do original alemão, realizada por Joaquim Ritter e Friedrich Bollnow. Adriano Mergulhão fez a tradução do apêndice IV e Deborah Guimarães traduziu o apêndice III, revisou as traduções, inseriu as notas (que serão acompanhadas da sigla " $N d R$ " - nota da revisora) e redigiu esta pequena apresentação. Optamos por manter como título deste documento o nome do texto principal do presente trabalho: a Disputa entre Cassirer e Heidegger. Contudo, por se tratar de um texto de grande relevância para os estudos sobre Kant, Heidegger, Cassirer e suas respectivas recepções, decidimos traduzir o terceiro item da seção de apêndices a fim de complementar a leitura, situando, com mais profundidade, a posição do debate no âmbito da recepção da filosofia transcendental.

\section{TRADUÇÕES}

\section{Conferências de Davos [Davoser Vorträge]}

\section{A Crítica da razão pura de Kant e a tarefa de uma fundamentação da metafísica}

Kants Kritik der reinen Vernunft und die Aufgabe einer Grundlegung der Metaphysik

[271] As preleções deveriam comprovar a tese: a Crítica da razão pura de Kant é uma, ou a primeira, fundamentação expressiva da metafísica. 
De modo negativo, isto é, contra a interpretação tradicional [traditionelle] do Neokantismo: ela não é uma teoria do conhecimento científico-natural-matemático - ela não é, de maneira alguma, teoria do conhecimento.

Por meio da elucidação dessa fundamentação da metafísica, deveria se esclarecer, ao mesmo tempo, que e como a pergunta sobre a essência do ser humano, no âmbito de uma "metafísica da metafísica", é essencial.

O peso principal das explicitações foi posto mediante a apresentação do percurso interno da problemática da fundamentação, dos passos principais e de sua necessidade.

De acordo com isso, a estrutura do todo divide-se em três partes:

1. A fundamentação da metafísica no ponto de partida,

2. A fundamentação da metafísica na realização,

3. A fundamentação da metafísica em sua originariedade.

Ad 1. O ponto de partida de Kant na metafísica tradicional [überlieferten] 3 determina a forma do problema. Uma vez que a metaphysica specialis perfaz o conhecimento do suprassensível (o todo do mundo, a alma [imortalidade], Deus), a "metafísica autêntica" (Kant), a pergunta sobre a sua possibilidade é, de maneira geral, a seguinte: como é possível o conhecimento sobre o ente [Erkenntnis von Seiendem] em geral? Na medida em que à possibilidade do conhecimento sobre o ente pertence a compreensão prévia da constituição de ser própria ao ente, a pergunta sobre a possibilidade do conhecimento ôntico é remetida à [questão] da possibilidade do [conhecimento] ontológico, isto é, a fundamentação da metaphysica specialis concentrase [272] na fundamentação da metaphysica generalis (Ontologia).

Mostra-se, então, como essa pergunta sobre a possibilidade da ontologia toma a forma do problema de uma "Crítica da razão pura".

\footnotetext{
3 NdR: Destacamos a distinção dos adjetivos empregados em alemão para se referir ao adjetivo "tradicional" em língua portuguesa devido à variação semântica entre eles. Traditionelle refere-se mais a certo conjunto de valores, crenças, convicções etc. que perpassa a interpretação de algo. Já o segundo adjetivo empregado, está diretamente relacionado ao substantivo Überlieferung, que tem em seu étimo o verbo liefern (entregar, transmitir). Nesse sentido, o adjetivo überlieferte designa aquilo que é transmitido, entregue pelas gerações passadas às gerações presentes e assim por diante, ou seja, resguarda um acento historicista.
} 
Ad 2. Para o entendimento da realização da fundamentação é decisivo que se torne claro que e como, previamente, a razão pura humana, isto é, finita, circunscreve sozinha o escopo da problemática. Com essa finalidade, é necessário expor o conhecimento finito em geral e os caracteres fundamentais da finitude como tal. A partir daí, advém, primeiramente, a visão do conceito metafísico - não psicológico e sensualista - da sensibilidade como intuição finita. Por ser finita, a intuição do ser humano necessita do pensar, que, como tal, é completamente finito. (A ideia de um pensar infinito é um contrassenso [Widersinn]).

O conhecimento finito consiste em "duas fontes fundamentais do ânimo" (sensibilidade e entendimento) ou em "dois troncos" que "talvez" "se originem de uma raiz comum, mas para nós desconhecida".

A elucidação da possibilidade do conhecimento ontológico (conhecimento sintético a priori) torna-se a pergunta sobre a essência de uma síntese "pura" (livre de experiência) de intuição pura e pensar puro.

Os estágios principais da realização da fundamentação são, portanto, os seguintes:

a) Exposição dos elementos da essência do conhecimento puro: isto é, da intuição pura (espaço e tempo) e do pensar puro (Estética transcendental e Analítica dos conceitos).

b) Caracterização da unidade essencial desses elementos na síntese pura ( $\$ 10$ da $2^{\mathrm{a}}$ edição).

c) Elucidação da possibilidade interna dessa unidade essencial, isto é, da síntese pura (Dedução transcendental). [273]

d) Desvelamento do fundamento da possibilidade da essência do conhecimento ontológico (capítulo do Esquematismo).

Ad 3. A fundamentação em sua originariedade.

Resultado do precedente: o fundamento da possibilidade do conhecimento sintético a priori é a imaginação transcendental. Kant introduziu, no decorrer da fundamentação, contrapondo-se ao ponto de partida diretriz, uma terceira fonte fundamental do ânimo.

Esta não reside "entre" ambos os troncos desenvolvidos, mas é a sua raiz. 
Isso é mostrado mediante a recondução da sensibilidade pura e do entendimento puro à imaginação [Einbildungskraft] - não apenas estes, mas a razão teórica $e$ prática em sua separação e em sua unidade.

O ponto de partida na razão foi, dessa forma, implodido.

Com isso, Kant levou a si mesmo, por meio de seu radicalismo, a uma posição diante da qual precisou recuar.

Ela significa: destruição das bases [Grundlagen] anteriores da metafísica ocidental (espírito, lógos, razão).

Ela requer um desvelamento radical e renovado do fundamento da possibilidade da metafísica como disposição natural do ser humano, isto é, uma metafísica do ser-aí [Dasein] direcionada à possibilidade da metafísica como tal, que deve colocar a pergunta sobre a essência do ser humano de um modo que se situe antes de toda antropologia filosófica e de toda filosofia da cultura.

\section{A disputa de Davos entre Ernst Cassirer e Martin Heidegger}

\section{Davoser Disputation zwischen Ernst Cassirer und Martin Heidegger}

[274] Cassirer: O que Heidegger compreende por Neokantismo? Quem é o adversário contra o qual Heidegger se dirigiu? Eu penso que dificilmente exista um conceito circunscrito de modo tão pouco distinto quanto o conceito de neokantismo. $\mathrm{O}$ que Heidegger tem em vista quando ele institui sua própria crítica fenomenológica no lugar da crítica neokantiana? O neokantismo é o bode expiatório [Sündenbock] da nova filosofia. Porém, para mim, falta o neokantiano existente. Eu ficaria grato por um esclarecimento sobre isso, onde propriamente se situa aqui a oposição. Eu creio que não resulta disso nenhuma oposição essencial. Deve-se determinar o conceito de "neokantismo" não de modo substancial, mas, sim, funcional. Não se trata de um tipo de filosofia como sistema doutrinário dogmático, mas de um direcionamento da colocação da pergunta. Preciso confessar que encontrei aqui, em Heidegger, um neokantiano, tal como eu nunca dele teria podido suspeitar.

Heidegger: Se, em primeiro lugar, eu devo citar nomes, então eu digo: Cohen, Windelband, Rickert, Erdmann, Riehl. O que é comum ao neokantismo só pode ser compreendido a partir de sua origem. Tal gênese é o constrangimento [Verlegenheit] da 
filosofia no que diz respeito à pergunta, sobre o que ainda lhe restava na totalidade do conhecimento. Em torno do ano 1850, aconteceu que as Ciências do Espírito, tal qual as Ciências Naturais, ocuparam a totalidade do que era cognoscível, então, desse modo, surgiu a questão: O que resta ainda à filosofia, se a totalidade do ente está dividida entre as ciências? Resta somente o conhecimento da ciência, não o do ente. E, sob esse ponto de vista, determinou-se então o regresso a Kant. Por conseguinte, Kant passou a ser visto como o teórico da teoria do conhecimento físico-matemática [275]. Teoria do conhecimento é o aspecto sob o qual Kant veio a ser visto. O próprio Husserl, entre 1900 e 1910, em certo sentido, caiu nos braços do neokantismo.

Eu compreendo por neokantismo a concepção da Crítica da Razão Pura, que explica como teoria do conhecimento, com referência à ciência natural, a parte da razão pura que conduz até a dialética transcendental. Com isso, quero demonstrar que aquilo que foi aqui extraído como teoria das ciências, para Kant, era algo inessencial. Kant não desejava fornecer nenhum tipo de Teoria da Ciência Natural, senão que queria mostrar a problemática da metafísica e, em verdade, a da Ontologia. No que diz respeito a mim, interessa-me trabalhar esse conteúdo central do elemento positivo da Crítica da Razão Pura inserindo-o positivamente na ontologia. Com base na minha interpretação da dialética como ontologia, penso poder mostrar que o problema da aparência [Problem des Scheins] na Lógica Transcendental, que ali, para Kant, se encontra apenas de modo negativo, tal como aparece primeiramente, é um problema positivo, no qual seria questionável: será a aparência [Schein] apenas um fato que nós constatamos, ou será que todo problema da razão deve ser concebido, de tal modo que se compreenda, de antemão, como a aparência [Schein] pertence necessariamente à natureza do ser humano?

Cassirer: Só se compreende Cohen corretamente quando o compreendemos historicamente, não meramente como o teórico do conhecimento. Eu não compreendo o meu próprio desenvolvimento como um resíduo [Abfall] de Cohen. Naturalmente, cheguei, no decorrer do meu trabalho, a muitas conclusões diversas, e eu, na verdade, reconheci, sobretudo, a posição da ciência natural matemática, mas ela só pode permanecer como um paradigma, não como a totalidade do problema. E o mesmo é válido para Natorp. Agora, sobre o problema sistemático central de Heidegger.

Em um ponto há concordância entre nós: que a imaginação produtiva, também para mim, parece ter, de fato, [276] um significado central para Kant. A partir desse ponto 
eu conduzi meu trabalho sobre o simbólico. Isso não pode ser resolvido sem que se reconduza à faculdade da imaginação produtiva. A imaginação é a relação de todo pensamento com a intuição. Kant chama a imaginação de synthesis speciosa. A síntese é o poder fundamental [Grundkraft]4 do pensamento puro. Para Kant, porém, esse [pensamento puro] não depende simplesmente da síntese, mas, em primeiro lugar, da síntese que se serve das espécies. Porém, esse problema das espécies conduz ao núcleo do conceito de imagem, do conceito de símbolo.

Quando se concebe a totalidade do trabalho de Kant, grandes problemas irrompem. Um dos problemas é o da liberdade. Esse sempre foi, para mim, o autêntico problema principal de Kant. Como a liberdade é possível? Kant diz que essa pergunta não pode ser compreendida desse modo. Nós só concebemos a incompreensibilidade da liberdade. Contrariamente a isso, gostaria de apresentar agora uma vez a ética kantiana: o imperativo categórico deve ser de tal modo disposto, que a lei constituída seja válida não só para os seres humanos, mas também para todo ser racional em geral. Subitamente, aqui reside essa notável transição. A limitação reduz-se subitamente a uma esfera determinada. O ético [Sittliche], como tal, conduz para além do mundo dos fenômenos. Isso é, contudo, o elemento metafísico decisivo, do qual agora sucede, nesse ponto, uma ruptura. Trata-se da transição ao mundus intelligibilis. Isso vale para o ético, e nele é atingido um ponto que não é mais relativo à finitude do ser cognoscente, mas, sim, é estabelecido ali então um Absoluto. Isso não pode ser elucidado historicamente. Pode-se dizer: um passo que Kant não poderia ter realizado. Mas nós não podemos negar o fato de que o problema da liberdade foi estabelecido desse modo, uma vez que ele rompe a esfera originária. Isso se refere à exposição de Heidegger. O extraordinário significado do esquematismo não pode ser superestimado [überschätzen]. [277] Nesse ponto, passaram inadvertidos os maiores equívocos na interpretação de Kant. Não obstante, no ético ele proíbe o esquematismo. Pois, ele diz: nossos conceitos de liberdade, e assim por diante, são evidências [Einsichten] (não conhecimentos [Erkenntnisse]) que não mais se deixam esquematizar. Há um esquematismo do conhecimento teórico, mas não da razão

4 NdR: O termo Grundkraft designa algo como uma capacidade fundamental. Em contextos mais amplos, o termo Kraft é, geralmente, traduzido por força. Porém, optamos por manter a proximidade com o léxico kantiano, que geralmente enfatiza o aspecto de possibilidade envolto no termo. É por esse motivo que Grundkraft é traduzido aqui por "poder fundamental". 
prática. Há, quando muito, algo diferente, ao qual Kant designa de típica da razão prática. E entre esquematismo e típica ele faz uma diferenciação. É preciso entender que não se pode penetrar aqui, caso não se abandone, nesse ponto, novamente o esquematismo. $\mathrm{O}$ esquematismo também é, para Kant, o terminus a quo, mas não o terminus ad quem. Na Crítica da Razão Prática ocorrem novos problemas, e esse ponto de partida do esquematismo é, na verdade, sempre mantido por Kant, mas também ampliado [erweitert]. Kant partiu do problema de Heidegger. Mas esse círculo foi por ele ampliado. Resumo [Zusammenfassung]: Essa ampliação foi, portanto, necessária, porque um problema permanece no ponto central: Heidegger pôs em evidência que nossa capacidade de conhecimento [Erkenntniskraft] é finita. Ela é relativa e está vinculada [gebunden]. Então, porém, resulta disso a pergunta: Como tal ser finito chega, de modo geral, ao conhecimento [Erkenntnis], à razão [Vernunft], à verdade [Wahrheit]?

E, agora, quanto às questões objetivas: Heidegger apresenta uma vez o problema da verdade e diz: não é possível que existam, em geral, verdades em si mesmas ou verdades eternas. Pelo contrário, existem verdades na medida em que são, em geral, efetivamente relativas ao ser-aí [Dasein]. Por conseguinte: um ser finito não pode, em geral, possuir verdades eternas. Não há, para o ser humano, verdades eternas e necessárias. E aqui todo o problema irrompe novamente. Para Kant, o problema era precisamente: Sem prejuízos para a finitude, a qual o próprio Kant assinala, como é possível, apesar de tudo, que existam verdades necessárias e universais? Como são possíveis os juízos sintéticos a priori? Tais juízos [278], os quais não são meramente finitos em seus conteúdos, mas que são, em seus conteúdos, universais e necessários? Esse é o problema que Kant exemplifica por meio da matemática: o conhecimento finito estabelece-se em relação com a verdade, de modo que não desenvolve, mais uma vez, um "somente" ["Nur"]. Heidegger disse que Kant não forneceu provas da possibilidade da matemática. Parece-me, creio eu, que a questão está bem colocada nos Prolegômenos, mas essa não é, e nem pode ser, a única pergunta. Mas também essa pergunta puramente teórica deve ser primeiramente esclarecida: Como esse ser finito chega a uma determinação de objetos, que, como tais, não estão vinculados à finitude? Agora, minha questão é a seguinte: Heidegger quer renunciar a toda essa objetividade, a essa forma de absolutidade que Kant defendeu no ético, no teórico e na Crítica da Faculdade de Julgar? Quer ele subtrair-se totalmente a esse ser finito ou, se não, onde está para ele a ruptura 
para essa esfera? Eu pergunto porque sinceramente eu ainda não sei. Pois, para Heidegger, temos inicialmente a fixação do ponto de passagem. Mas creio que Heidegger não pode, nem deseja, permanecer parado nisso. Ele próprio deve se colocar novamente essas questões. E então, creio eu, problemas absolutamente novos virão à tona.

Heidegger: Em primeiro lugar, acerca da questão das ciências naturais e matemáticas. Pode-se dizer que a natureza, como uma região própria ao ente, não era, para Kant, uma região qualquer. Natureza nunca quis dizer, em Kant: objeto da ciência natural matemática, mas que o ente da natureza é o ente no sentido do estar presente à mão [Vorhandenen].5 O que Kant realmente queria oferecer na Doutrina dos Princípios não é uma doutrina estrutural categorial do objeto da ciência natural matemática. O que ele queria era uma teoria do ente em geral (Heidegger justifica isso). Kant busca uma teoria do ser em geral sem aceitar objetos que fossem dados, sem aceitar [279] uma região determinada do ente (nem a psíquica nem a física). Ele procura uma ontologia geral, que se situe antes de uma ontologia da natureza como objeto da ciência natural e antes de uma ontologia da natureza como objeto da psicologia. O que eu quero mostrar é que a Analítica não é somente uma ontologia da natureza como objeto da ciência natural, mas, sim, uma ontologia geral, uma metaphysica generalis fundada criticamente. O próprio Kant diz: a problemática dos Prolegômenos, que ele ilustra [com a pergunta sobre] como é possível a ciência da natureza etc., não é o motivo central, mas essa é a pergunta acerca da possibilidade da metaphysica generalis ou de sua própria execução.

Agora, porém, o outro problema da imaginação. Cassirer igualmente quer mostrar que a finitude se torna transcendente nos escritos éticos. - No imperativo categórico situase algo que ultrapassa o ser finito. Mas justamente o conceito de imperativo como tal mostra a referência interna a um ser finito.6 Mesmo essa ultrapassagem em direção a um

5 NdR: O termo Vorhandenheit é o substantivo que se refere aos entes que estão presentes à mão. Formado a partir da junção do prefixo "vor", preposição que significa em frente ou à frente de, com a palavra Hand, mão, o intuito do emprego desse termo é caracterizar o modo de ser próprio aos entes subsistentes, isto é, aos entes dotados de propriedades. Vorhandenen diz respeito, portanto, aos próprios entes. Vorhandenheit, ao caráter de ser desses entes.

6 NdR: Procuramos traduzir Wesen sempre por ser, assim como Sein; e Seiende, por ente. Cabe citar que Seiende é um termo formado a partir do particípio presente do verbo sein (ser), isto é, a partir da junção da 
ponto mais elevado é sempre uma ultrapassagem para o ser [Wesen] finito, para a criatura [Geschaffenen] (Anjo). Também essa transcendência permanece ainda no interior do caráter-de-ser da criatura [Geschöpflichkeit] e da finitude. Essa referência interna, que se situa no próprio imperativo, e a finitude da Ética, se sobressai em um lugar onde Kant fala sobre a razão do ser humano como automantenedora, isto é, uma razão puramente mantida por si própria, que não pode se refugiar no eterno, no absoluto, mas que tampouco pode se refugiar no mundo das coisas. Esse entremeio [Dazwischen] é a essência7 da razão prática. Eu acredito que se equivoca na interpretação ética kantiana quando se está previamente orientado para aquilo a que se dirige o agir ético e quando pouco se deixa de ver a função interna da própria lei para o ser-aí [Dasein]. Não se pode discutir o problema da finitude do ser moral, se não se coloca a questão: O que a lei significa aqui e como se constitui a própria legalidade para o ser-aí [Dasein] e para a personalidade? [280]. Que exista algo na lei que ultrapassa a sensibilidade não deve ser negado. Mas a pergunta é: como é a estrutura interna do próprio ser-aí [Dasein], ela é finita ou infinita?

Nessa pergunta sobre a ultrapassagem da finitude há um problema totalmente central. Eu disse que se trata de uma questão peculiar colocar a pergunta acerca da possibilidade da finitude em geral. Pois, pode-se simplesmente argumentar de modo formal. Tão logo eu declare algo sobre o finito e queira definir o finito como finito, já é preciso que eu tenha uma ideia da infinitude. Por ora, isso não diz muito. Porém, ao menos, tanto já diz, que existe aqui um problema central. Agora, eu quero deixar claro que, precisamente no conteúdo do que se evidencia como constitutivo da finitude, manifesta-se esse caráter da infinitude, como eu disse: Kant designa a imaginação, no esquematismo, como exhibitio originaria. No entanto, essa originariedade é uma exhibitio, uma tal apresentação [Darstellung], do livre dar-se [freien Sichgebens], no qual reside uma dependência de um acolhimento [Hinnehmen]. Então, na verdade, essa originariedade, de certo modo, está aí como uma faculdade criadora [schöpferisches Vermögen]. O ser humano, como ser [Wesen] finito, tem uma certa infinitude no ontológico. Mas o ser humano nunca é infinito e absoluto na criação do próprio ente

letra "d" a fim de sinalizar o caráter de presente dessa ação. Portanto, Seiende é o que está sendo, portanto, ente, tal como é possível traduzir seguindo o particípio presente do vocábulo latino.

${ }_{7} N d R$ : O termo aqui traduzido por essência é também Wesen, que pode significar tanto a essência própria a algo ou, por extensão, o ser de algo. 
[Seienden], mas ele é infinito no sentido da compreensão de ser [Sein]. Porém, na medida em que, como diz Kant, a compreensão ontológica do ser somente é possível na experiência interna própria ao ente, essa infinitude do ontológico está essencialmente ligada à experiência ôntica, de modo que é necessário dizer o inverso: Essa infinitude, a qual irrompe na imaginação, é justamente o mais agudo argumento para a finitude. Pois a ontologia é um index da finitude. Deus não a possui. E como o ser humano possui a exhibitio, esse é o argumento mais agudo de sua finitude. Pois somente um ser [Wesen] finito necessita de ontologia.

Levanta-se então o contra-argumento de Cassirer, com referência ao conceito de verdade. Em Kant, o conhecimento ontológico [281] é universalmente necessário, o qual toma antecipadamente todas as experiências fáticas; no que eu, em seguida, posso chamar a atenção sobre o fato de que Kant diz, em muitas passagens, que o que torna a experiência possível, a possibilidade interna do conhecimento ontológico, é contingente. - A própria verdade está unida pelo mais íntimo acordo com a estrutura da transcendência, de modo que o ser-aí [Dasein] seja um ente que está aberto para os outros e para si próprio. Nós somos um ente que se mantém no desvelamento [Unverborgenheit] próprio ao ente. Manter-se assim na manifestabilidade [Offenbarkeit] própria ao ente é o que eu designo como ser-na-verdade [In-der-Wahrheit-sein], e eu vou mais distante e digo: no fundamento da finitude do ser-na-verdade do ser humano há, simultaneamente, um serna-não-verdade [In-der-Unwahrheit-sein]. A não-verdade pertence ao núcleo mais interno da estrutura do ser-aí [Dasein]. E, aqui, creio eu ter encontrado primeiramente a raiz onde a "aparência" [Schein] metafísica de Kant é fundamentada metafisicamente.

Agora, quanto à pergunta de Cassirer sobre as verdades eternas universalmente válidas. Se eu digo: a verdade é relativa ao ser-aí [Dasein], esta não é, então, uma afirmação ôntica no sentido em que falo: verdadeiro é sempre e somente o que o ser humano individual pensa. Ao contrário, trata-se de uma sentença metafísica: a verdade só pode ser, em geral, como verdade e [enquanto verdade] possui apenas um sentido, se o ser-aí existe. Se o ser-aí não existisse, não haveria verdade, então não haveria absolutamente nada. Mas com a existência de algo como o ser-aí, a verdade vem primeiramente ao próprio ser-aí. Agora, porém, a pergunta: Como isso se sustenta com a validade da eternidade da verdade? Essa pergunta sempre se orienta segundo o problema da validade, a sentença pronunciada, e, primeiramente, a partir daí, retorna-se àquilo que 
é válido. E com relação a isso se encontram os valores ou coisas semelhantes. Eu creio que o problema precisa ser desenvolvido [aufgerollt] de forma diferente. A verdade é relativa ao ser-aí. Com isso, não é dito que não haveria nenhuma possibilidade de que o ente [Seiende] se manifestasse, tal como ele é, para qualquer um. Porém, eu diria que essa supra-subjetividade [Übersubjektivität] da verdade [282], essa irrupção da verdade sobre a própria singularidade como ser-na-verdade, já significa estar entregue ao próprio ente [Seiende], ser transferido para a possibilidade de se autoconfigurar [es selbst zu gestalten]. O que é, aqui, redimível como conhecimento objetivo tem, conforme a respectiva existência particular fática, um conteúdo de verdade, o qual, enquanto conteúdo, diz algo sobre o ente [Seiende]. A peculiar validade, que lhe é atribuída, é mal interpretada quando se diz: em contraposição ao fluxo da vivência há algo permanente, o eterno, o sentido e o conceito. Eu coloco uma réplica: então, o que propriamente quer dizer aqui eterno? De onde sabemos, então, sobre essa eternidade? Essa eternidade não é somente a constância no sentido do àzí do tempo? Essa eternidade não é somente aquilo que é possível a partir do fundamento de uma transcendência interna do próprio tempo? Toda minha interpretação da temporalidade tem esse propósito metafísico de indagar: todos esses

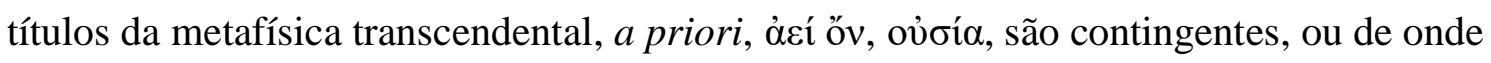
eles provêm? Se eles falam do eterno, como devem ser compreendidos? Eles somente devem ser compreendidos e só são possíveis na medida em que na essência [Wesen] do tempo reside uma transcendência interna, pois o tempo não é só o que possibilita a transcendência, mas sim que o próprio tempo tem em si um caráter horizontal, e que eu, no comportamento futuro e na rememoração, sempre tenho, simultaneamente, um horizonte em geral de presente [Gegenwart], futuridade [Künftigkeit]8 e preteridade [Gewesenheit] 9 , que se encontra, aqui, uma determinação temporal transcendentalmente

8 NdR: Künftigkeit é um termo que designa o caráter de futuro presente na ekstase temporal do porvir. Enquanto Zukunft significa o substantivo "futuro", künftig é o adjetivo usado para qualificar algo como futuro. Nesse caso, com a junção desse adjetivo ao prefixo “-keit”, o que está em jogo é o caráter de futuro que acompanha a abertura do horizonte transcendental da pergunta pelo ser: o tempo. É nesse sentido que o tradutor emprega o termo "futuridade".

9 NdR: Preteridade é uma alternativa de tradução para o termo Gewesenheit, formado a partir do particípio passado do verbo sein (ser), gewesen, e do sufixo -heit, geralmente usado na formação de substantivos a 
ontológica, dentro da qual, em primeiro lugar, se constitui algo como a permanência da substância. - É por esse lado que toda a minha interpretação da temporalidade precisa ser compreendida. E para que essa estrutura interna da temporalidade seja destacada e também para mostrar que o tempo não é somente um quadro [Rahmen] no qual as vivências transcorrem, a fim de tornar manifesto esse caráter interno da própria temporalidade no ser-aí [Dasein], foi necessário o esforço de meu livro. Cada página deste livro foi escrita unicamente em vista disso, que o problema do ser [Seinsproblem], desde a antiguidade e sempre no decorrer do tempo, foi interpretado [283] em um sentido totalmente incompreensível de que o tempo sempre foi atribuído ao sujeito. Com vistas ao nexo dessa questão com o tempo, assim como à pergunta sobre o ser em geral [Sein überhaupt], foi necessário expor, em primeiro lugar, a temporalidade do ser-aí [Dasein], não no sentido de que seria trabalhada por alguma teoria, mas sim de que, em uma problemática totalmente definida, será colocada a questão do ser-aí humano. - Toda essa problemática em "Ser e Tempo", que lida com o ser-aí no humano, não é uma Antropologia Filosófica. Para tal fim, ela é demasiadamente estreita e provisória. Eu acredito que existe uma problemática que, como tal, não foi até agora desenvolvida, uma problemática que é definida por meio da questão: se a possibilidade da compreensão de ser [Seinsverständnis] e, com isso, a possibilidade da transcendência do ser humano e, com isso, a possibilidade do comportamento configurador [des gestaltenden Verhaltens] para com o ente [Seienden], do acontecimento histórico na história do mundo do próprio ser humano, deve ser possível, e quando essa possibilidade estiver fundamentada em uma compreensão de ser e, se essa compreensão ontológica estiver orientada em qualquer sentido para o tempo, então, eis a tarefa: com vistas à possibilidade de compreensão de ser, expor a temporalidade do ser-aí [Dasein]. Para tal, serão orientados todos os problemas. A análise da morte tem por função, em determinada direção, expor a radical futuridade do ser-aí [Dasein] e não expor totalmente uma tese derradeira e metafísica da essência da morte [Wesen des Todes]. A análise da angústia [Angst] tem por única função, não tornar evidente um fenômeno central do ser humano, mas preparar a pergunta: Com base em qual sentido metafísico do próprio ser-aí [Dasein] é possível que o ser humano possa ser em geral confrontado com algo como o nada? A análise da angústia é colocada

partir de outras classes gramaticais. Portanto, Gewesenheit é o caráter próprio àquilo que é sido, algo como uma "sididade" ou o caráter de "ter-sido". 
em consequência disso, por conseguinte, que a possibilidade de algo como o nada possa ser pensado somente como ideia, seja fundamentada a partir dessa determinação da disposição10 da angústia. Somente quando compreendo o nada ou [284] a angústia, tenho a possibilidade de compreender ser. Ser é incompreensível se o nada é incompreensível. E só na unidade da compreensão de ser e de nada surge a pergunta pela origem do porquê [Warum]. Por que o ser humano pode perguntar sobre o porquê e por que ele deve perguntar? Esse problema central do ser [Sein], do nada e do porquê são os mais elementares e os mais concretos. Esses problemas são aquilo para o que toda a analítica do ser-aí [Dasein] se orientou. E creio eu que, partindo dessa antecipação, já se pode vislumbrar que toda suposição sob a qual a crítica de Ser e Tempo repousa não encontrou o verdadeiro âmago de meu desígnio, mas, por outro lado, eu posso me dar por satisfeito pois, de certo modo, quando essa analítica do ser-aí em Ser e Tempo se completa como uma investigação sobre o ser humano e, então, se coloca a pergunta sobre como o fundamento dessa compreensão do ser humano deve ser possível a partir da compreensão de uma configuração da cultura e das esferas culturais, de modo que, caso se faça essa pergunta dessa maneira, isso se mostre como uma impossibilidade absoluta de dizer algo sobre o que jaz aqui. Todas essas perguntas são inadequadas no que diz respeito ao meu problema central. Eu coloco, simultaneamente, uma outra pergunta metodológica: como deve então ser estabelecida uma tal metafísica do ser-aí [Dasein], a qual tenha o fundamento de sua determinação no problema de conquistar um solo para o problema da própria possibilidade da metafísica? Não lhe serve de fundamento uma determinada visão de mundo? Eu me equivocaria se dissesse que ofereceria uma filosofia livre de pontos de vista. E aqui se expressa um problema: o [problema] das relações entre filosofia e visão de mundo. A filosofia não tem por tarefa fornecer uma visão de mundo, porém, ao contrário, a visão de mundo é o pressuposto do filosofar. E a visão de mundo que o filósofo fornece não é direta no sentido de uma doutrina, nem no sentido de uma influência, mas é a visão de mundo, fornecida pelo filósofo, que se baseia no fato de que no filosofar se sucede [um] tornar radical a transcendência do próprio ser-aí [Dasein] [285], isto é, a possibilidade interna desse ser [Wesen] finito comportar-se em relação ao

10 NdR: O termo aqui traduzido por "disposição" é Befindlichkeit. Este designa o modo como alguém se encontra disposto. Além de um caráter meramente local, possui, sobretudo, um acento modal. O termo é a junção do verbo sich befinden com o sufixo -keit. 
ente [Seienden] na totalidade. Colocando de outro modo: Cassirer diz: Nós não concebemos [begreifen] a liberdade, mas somente o inconcebível [Unbegreiflichkeit] da liberdade. A liberdade não se deixa conceitualizar [begreifen]. A pergunta: Como a liberdade é possível? é contraditória [widersinnig]. Disso, porém, não se segue que, de certo modo, aqui permanece um problema irracional, mas antes porque a liberdade não é objeto de apreensão teórica, pois, ao contrário, ela é um objeto do filosofar, assim isso não significa outra coisa senão que a liberdade somente é, e somente pode existir, no libertar-se. A única referência adequada para a liberdade do ser humano é o libertar-se da liberdade no ser humano.

Para penetrarmos nessa dimensão do filosofar, o que não é objeto de nenhuma discussão erudita, mas sim alguma coisa sobre a qual o filósofo singular nada sabe, e que é uma tarefa à qual o filósofo tem de se curvar, essa libertação do ser-aí [Dasein] no ser humano deve ser a [tarefa] única e central que a filosofia como filosofar pode realizar. E nesse sentido eu acreditaria que, em Cassirer, existe um terminus ad quem totalmente diferente, no sentido de uma filosofia da cultura, de modo que essa questão da filosofia da cultura só obtém sua função metafísica no acontecimento da história da humanidade, caso ela não permaneça e nem se mostre como uma mera apresentação [Darstellung] das diferentes regiões, mas se, ao mesmo tempo, ela se tornar, de tal modo, tão enraizada em sua dinâmica interna, que ela, desde o princípio e não ulteriormente, torne-se expressamente visível na metafísica do próprio ser-aí [Dasein] enquanto acontecimento fundamental.

Perguntas para Cassirer:

1. Que caminho possui o ser humano para a infinitude? E como é o modo pelo qual o ser humano pode participar da infinitude?

2. A infinitude deve ser conquistada como determinação privativa da finitude, ou a infinitude é um domínio próprio? [286]

3. Até que ponto a filosofia tem a tarefa de se tornar livre da angústia? Ou, então, não tem ela justamente a tarefa de entregar radicalmente o ser humano à angústia?

Cassirer:

Ad.1 Não de outro modo senão por meio [Medium $]$ da forma. Essa é a função da forma, que o ser humano, na medida em que transforma seu ser-aí [Dasein] em forma, isto é, 
enquanto ele transforma tudo que é vivenciado internamente em forma objetiva, na qual ele de tal modo se objetiva, que, com isso, ele não se torna livre da finitude radical do ponto de partida (pois isso ainda demonstra sua própria finitude), mas, na medida em que cresce da finitude, ele a conduz em direção a algo novo. E isso é a infinitude imanente. $O$ ser humano não pode dar o salto de sua própria finitude para uma infinitude realista.

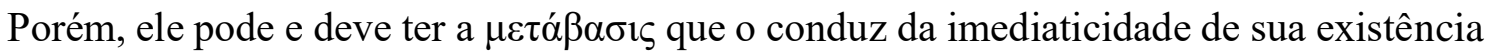
para dentro da região da forma pura. E ele possui sua infinitude unicamente nessa forma. "Do cálice deste reino do espírito, flui para ele a infinitude" (Goethe). O reino do espírito não é um reino metafísico do espírito; o autêntico reino do espírito é justamente aquele mundo espiritual criado por ele próprio. Que ele pôde criá-lo, é o selo de sua infinitude.

Ad.2 Não é somente uma determinação privativa, mas um domínio próprio, porém, não um domínio que fosse apenas conquistado de maneira puramente negativa para a finitude; não é apenas um antagonismo para com a finitude que a infinitude é constituída, porém, em certo sentido, trata-se justamente da totalidade da consumação [Erfüllung] da própria finitude. Mas essa consumação da finitude constitui justamente a infinitude. Goethe: "Queres tu caminhar no infinito, segue somente no finito em todos os lados!" Quando a finitude se completa [erfüllt], isto é, ela vai para todos os lados, ela caminha para além da infinitude. Isso é o contrário de privação, é o preenchimento [Ausfüllung] perfeito da própria finitude.

[287] Ad.3 Essa é uma questão completamente radical, à qual somente se pode responder ao modo de uma confissão. A filosofia só pode deixar o ser humano ser livre na medida em que ele pode se tornar livre. Quando ela faz isso, creio eu que ela certamente o liberta, em certo sentido, radicalmente, da angústia como mera disposição. Eu creio que, mesmo após as exposições de Heidegger hoje pela manhã, a liberdade somente pode ser encontrada no caminho da libertação progressiva, o qual, também para ele, é um processo interminável. Eu creio que ele pode concordar com essa interpretação. Ainda que eu veja que aqui repousa o problema mais difícil. Eu gostaria que o sentido, que a meta, fosse 
realmente a libertação, no seguinte sentido: "Lançai a angústia mundana11 de vós" Esta é a posição do idealismo, a qual eu sempre professei.

Pos:12 Observação Filológica: Ambos os senhores falam uma linguagem13 totalmente diferente. Para nós, portanto, trata-se de, nessas duas linguagens, retirar algo em comum. Da parte de Cassirer, já se fez uma tentativa de tradução em seu "espaço de ação" [“Aktionsraum”]. Nós precisamos averiguar se Heidegger reconhece essa tradução. A possibilidade de tradução chega até o ponto no qual algo, que não se deixa traduzir, emerge. Esses são os termos [Termini] que surgem como característicos de cada uma das linguagens. Eu tentei reunir, em ambas as linguagens, alguns desses termos, os quais eu desconfio que não se deixem traduzir na outra linguagem. Nomeio as expressões de Heidegger: o Dasein, o Ser, o ôntico. Por outro lado, as expressões de Cassirer: o funcional no espírito e a transformação do espaço originário em um outro. Poder-se-ia pensar que não há tradução de ambos os lados para esses termos, pois seriam os termos nos quais o espírito da filosofia de Cassirer e de Heidegger se diferenciam.

[288] Heidegger: Cassirer utilizou na primeira conferência as expressões: Terminus a quo e Terminus ad quem. Poder-se-ia dizer que o terminus ad quem em Cassirer é a totalidade de uma filosofia da cultura no sentido de clarificar a totalidade das formas da consciência configuradora [Formen des gestaltenden Bewußtseins]. O terminus a quo em Cassirer é completamente problemático. Minha posição é inversa: o terminus a quo é minha problemática central, a qual eu desenvolvo. A questão é: o terminus ad quem é, em mim, tão claro? Para mim, ele não consiste na totalidade de uma filosofia da cultura, mas, sim,

11 NdR: O termo aqui traduzido por "mundana" é des Irdischen, que significa, no presente contexto, do terrestre, do terreno, isto é, a angústia própria ao mundo dos seres humanos, cujo vínculo com a terra é imprescindível. A sentença toda é "Werft die Angst des Irdischen von euch!", que significa literalmente, "lançai (para longe, afastai) de vós a angústia do terrestre, do mundano".

12 NdR: Trata-se de uma questão colocada por Hendrik Josephus Pos (1898-1955), filósofo e linguista holandês. Também conhecido como H. J. Pos.

13 NdR: O termo Sprache é aqui traduzido sem o rigor que diferencia os vocábulos língua e linguagem na língua portuguesa. Em alemão, ambos (língua e linguagem) são concebidos pela palavra Sprache. Podemos supor que se trata, neste trecho, de língua, mas evitaremos adentrar esse nível de discussão, uma vez que o que está em jogo é destacar o léxico empregado, sobretudo, na economia das obras de Cassirer e de Heidegger. 


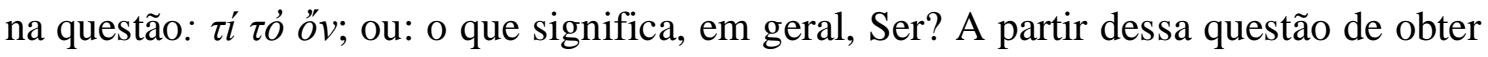
um solo para o problema fundamental da Metafísica, surgiu, para mim, a problemática de uma metafísica do ser-aí [Dasein]. Ou, para voltarmos mais uma vez ao núcleo da interpretação de Kant: meu intuito não era o de trazer algo novo perante uma interpretação da teoria do conhecimento, com honra à imaginação, mas deveria ficar claro que a problemática interna da Crítica da Razão Pura, isto é, a pergunta pela possibilidade da ontologia, remete a uma ruptura radical daquele conceito no sentido tradicional, que, para Kant, era o ponto de partida. Kant foi impelido por isso, na tentativa de uma fundamentação da Metafísica, de modo a fazer do próprio solo um abismo [Abgrund].

Quando Kant diz: as três perguntas fundamentais deixam-se conduzir à quarta: "O que é o ser humano?", então essa pergunta, em seu caráter de pergunta, torna-se questionável. Eu tentei mostrar que não é assim tão evidente partir de um conceito de Logos, mas sim que a questão acerca da possibilidade da metafísica exige uma metafísica do próprio ser-aí [Dasein] como possibilidade do fundamento de uma questão da metafísica, de forma que a pergunta sobre o que é o ser humano não devesse assim ser respondida no sentido de um sistema antropológico, mas devesse ser esclarecida primeira e propriamente no que concerne à perspectiva a partir da qual ela queira ser apresentada. E, aqui, eu retorno aos conceitos de terminus a quo e de terminus ad quem [289]. Isso é apenas um questionamento heurístico ou reside na essência da própria Filosofia que ela tenha um terminus a quo, que deve se tornar um problema, e que ela tenha um terminus ad quem que se mantém em uma correlação com o terminus a quo? Me parece que essa problemática não foi devidamente caracterizada [herausgeprägt] na filosofia de Cassirer até aqui, primeiramente, Cassirer vai evidenciar as diversas formas de configuração, para então, posteriormente, com vistas a essas configurações, expor uma certa dimensão dessas próprias forças configuradoras. Agora, poder-se-ia dizer: essa dimensão é, pois, em seu fundamento, o mesmo que aquilo que eu chamo de ser-aí [Dasein]. Mas isso seria errôneo. A diferença está, o mais claramente possível, no conceito de liberdade. Eu falei de uma libertação no sentido de que a libertação da transcendência interior do ser-aí [Dasein] é o caráter fundamental do próprio filosofar. No entanto, o sentido autêntico dessa libertação não se deixa situar no tornar-se livre, em certa medida, para as imagens configuradoras da consciência e para o reino da forma, mas sim, no tornar-se livre para a finitude do ser- 
aí [Dasein]. Justamente, para penetrar no cerne do ser-jogado14 do ser-aí [Dasein], penetrar no conflito que se situa na essência da liberdade. Eu não dei para mim mesmo a liberdade, embora eu só possa ser eu mesmo por meio do ser-livre [Freisein]. Mas, agora, "eu mesmo" não no sentido de um fundamento indiferente de explicitação, mas sim: que o ser-aí [Dasein] é o acontecimento fundamental autêntico, no qual a existência do ser humano e, com isso, toda problemática da própria existência, torna-se essencial.

A partir daí, acredito, pode-se dar uma resposta à questão de Pos sobre a tradução. Eu creio que aquilo que eu designo como Dasein não se deixa traduzir com um conceito de Cassirer. Se fosse dito consciência, então isso seria exatamente aquilo que seria recusado por mim. O que nomeio ser-aí [Dasein] é essencialmente codeterminado, não somente por meio do que se designa como espírito e tampouco somente por meio daquilo [290] que se chama de vida, mas sim, aquilo sobre o que ele depende é a unidade originária e a estrutura imanente de uma vinculação [Bezogenheit] do ser humano, o qual, de certo modo, está preso em um corpo e no aprisionamento no corpo está a própria vinculação com o ente [Seienden], em meio ao qual ele se encontra, não no sentido de um espírito que olha para baixo, mas no sentido de que o ser-aí [Dasein] jogado em meio ao ente [inmitten des Seienden geworfen], perfaz, enquanto liberto, uma irrupção no ente [Seienden], a qual é sempre histórica e, em sentido último, contingente.

Tão contingente, que a mais alta forma da existência do ser-aí [Dasein] só se deixa reconduzir sobre muitos, poucos e raros, instantes da duração do ser-aí [Dasein] entre vida e morte, que o ser humano, apenas em raros instantes, existe no auge de sua própria possibilidade e, não obstante, de outra forma, se move em meio ao seu ente.

A questão do modo de ser [Seinart] que está contida em sua filosofia das formas simbólicas, a questão central acerca da constituição interna do ser, é o que a metafísica do ser-aí [Dasein] determina - e essa questão não se determina com o propósito de uma sistemática previamente dada nos âmbitos da cultura [Kulturgebiete] e das disciplinas filosóficas. Em todo o meu trabalho filosófico eu deixo perfeitamente colocadas de fora

\footnotetext{
14 NdR: Ser-jogado é uma alternativa de tradução para o termo Geworfenheit, formado a partir do particípio passado do verbo werfen, que significa jogar, lançar ou, até mesmo, parir. Nesse sentido, o sufixo -heit serve para substantivar o particípio concedendo-lhe o sentido de algo que possui o caráter de "ser-jogado" ou "ser-lançado" abruptamente no mundo. Literalmente, e mantendo a criação de um neologismo, seria algo como uma "jogadidade”, isto é, o caráter de ser-jogado próprio ao ser-aí humano.
} 
a forma [Gestalt] e a divisão das disciplinas filosóficas porque eu penso que tal orientação é a maior fatalidade, uma vez que não retornamos mais à problemática interna da Filosofia. Tanto Platão quanto Aristóteles nada sabiam de uma tal divisão da filosofia. Uma tal divisão era tema das escolas, isto é, de uma tal filosofia na qual a problemática interna das questões foi perdida; e é necessário esforço para, a partir daí, romper com tais disciplinas. E, na verdade, é por conta disso que nós, quando passamos através da disciplina da Estética, entre outras, nós retornamos novamente ao modo de ser especificamente metafísico relativo às respectivas áreas. A arte não é somente uma forma da autoconsciência configuradora [sich gestaltenden Bewußtseins], mas a [291] própria arte tem um sentido metafísico no interior do acontecimento fundamental do próprio seraí.

Eu acentuei propositalmente essas diferenças. Não é útil ao trabalho objetivo se nós chegarmos a um nivelamento. Ao contrário, porque só por meio do rigor na evidenciação do problema, este obtém clareza, eu desejaria então que, mais uma vez, toda nossa discussão se colocasse sob o signo da Crítica da Razão Pura de Kant, e que, mais uma vez, se fixasse a questão sobre "o que é o ser humano?", como a questão central. Porém, essa questão, simultaneamente, como uma questão que não colocamos em um sentido ético isolado, mas, de maneira que sobre essa problemática ambas as posições se tornem claras, a questão acerca do ser humano, para o filósofo, só se torna essencial na medida em que o filósofo, pura e simplesmente, abstrai de si mesmo, por conseguinte, que a questão não pode ser colocada antropologicamente, mas deve ser mostrado: que por meio disso o ser humano é a essência [Wesen], o transcendente, ou seja, é aberto para o ente na totalidade e para si próprio, que o ser humano, ao mesmo tempo, por meio desse caráter excêntrico, também é colocado no interior da totalidade própria ao ente em geral - e que, somente assim, a questão e a ideia de uma antropologia filosófica obtêm sentido. Não no sentido de que o ser humano fosse examinado empiricamente como objeto dado, tampouco que eu projetasse uma antropologia do ser humano, mas a questão acerca da essência do ser humano somente tem o sentido e o direito quando ela é motivada a partir da problemática central da própria filosofia, na qual o ser humano é conduzido além de si mesmo e para dentro do todo próprio ao ente, tornando manifesto para ele, em toda sua liberdade, a nulidade [Nichtigkeit] do seu ser-aí. Uma nulidade que não é causa de pessimismo e melancolia, mas para a compreensão do fato de que efeitos autênticos só 
existem onde há oposição, e que a filosofia tem a tarefa de, a partir do aspecto de um ser humano preguiçoso que, em certo sentido, meramente utiliza as obras do espírito [Werke des Geistes], devolvê-lo à dureza de seu destino.

[292] Cassirer: Também eu sou contra um tal nivelamento. O que nós queremos e devemos aspirar, e que também podemos alcançar, é que cada um, ao permanecer em sua posição, não veja com isso somente a si mesmo, mas também o outro. Que isso deva ser possível, parece-me residir na ideia do conhecimento filosófico em geral, em uma ideia que Heidegger também reconhece. Eu não quero fazer a tentativa de retirar Heidegger de sua posição [Position] e coagi-lo a outra perspectiva, mas quero somente tornar sua posição compreensível para mim.

Eu creio que isso já tornou mais claro onde reside a oposição. Porém, não é frutífero acentuá-la sempre novamente. Nós estamos em uma posição na qual pouco é obtido por meio de meros argumentos lógicos. Ninguém pode ser forçado a assumir essa posição, e nenhuma coação através de argumentos puramente lógicos pode obrigar alguém a começar pela posição que, para mim, parece ser a essencial. Aqui estaríamos nós submetidos a uma relatividade. "Que tipo de Filosofia se escolheria depende do tipo de ser humano que se é”. Mas nós não podemos permanecer junto a essa relatividade, na qual o ser humano empírico seria colocado no centro. E foi muito importante o que Heidegger disse por último.

Sua posição [Stellung] também não pode ser antropocêntrica, e se ela assim não quer ser, eu pergunto, onde reside então o centro comum em nossa oposição. Que este não pode estar no empírico, está claro. Nós devemos, precisamente na oposição, procurar novamente pelo centro comum. E eu digo, nós não precisamos procurar. Pois nós temos esse centro, e, na verdade, isso é assim porque há um mundo humano objetivo e comum, no qual a diferença dos indivíduos não foi, então, suspensa de modo algum, mas com a condição de que aqui, então, as pontes de indivíduo para indivíduo foram lançadas. Isso se apresenta repetidamente para mim no fenômeno originário da linguagem. Cada um fala sua linguagem, [293] e é impensável que a linguagem de um seja traduzida para a linguagem do outro. E assim mesmo nos entendemos, através do meio [medium] da linguagem. Há algo assim como "a" linguagem. E algo assim como uma unidade acima da infinidade dos diferentes modos de fala [Sprechweisen]. Para mim, aí reside o ponto decisivo. E eis porque eu parto da objetividade da forma simbólica, porque aqui aconteceu 
o incompreensível. A linguagem é o exemplo mais nítido. Afirmamos que pisamos aqui em um solo comum. Primeiramente, asseveramos isso como postulado. E, apesar de todos os enganos, nós não nos enganaremos com essa reivindicação. É isso o que eu gostaria de chamar de mundo do espírito objetivo. A partir do ser-aí [Dasein] é tecido o fio que, através do meio [medium] de um tal espírito objetivo, novamente nos conecta com outro ser-aí [Dasein]. Eu creio que não há nenhum outro caminho de um ser-aí [Dasein] para outro ser-aí [Dasein] senão por meio desse mundo das formas. Há esse fato [Faktum]. Se não houvesse isso, então eu não saberia de que modo poderia haver algo como um entendimento mútuo. Também o conhecimento é apenas um caso fundamental dessa afirmação: que se possa formular um enunciado objetivo sobre uma coisa e que ela tenha o caráter da necessidade, que não leva mais em consideração a subjetividade do singular.

Heidegger corretamente afirmou que a questão básica de sua metafísica é a mesma de Platão e Aristóteles: o que é o ente? [Seiende]. Ele também afirmou que Kant tinha mais uma vez se referido a essa questão, que é fundamental a todas as metafísicas. Eu o admito sem mais delongas. Mas, aqui, parece-me existir uma diferença essencial, com respeito ao que Kant chama giro copernicano [kopernikanische Wendung]. De fato, a questão do ser não me parece, de forma alguma, ter sido eliminada por meio desse giro. Essa seria uma interpretação completamente falsa. Mas como resultado desse giro, a questão do ser [Seinsfrage] agora parece ter tomado uma forma muito mais complicada do que aquela que tinha na antiguidade. Em que consiste o giro [Wendung]? “Anteriormente foi aceito que o conhecimento precisava conformar-se ao objeto... [294] Porém, agora nós tentamos inverter a pergunta, como seria se não fosse nosso conhecimento que precisasse se conformar ao objeto, mas, pelo contrário, se fosse o objeto que devesse se conformar ao conhecimento?” Isso significa que essa pergunta pela determinação dos objetos é precedida por uma pergunta referente à constituição do ser [Seinskonstitution] de uma objetividade [Gegenständlichkeit] em geral. E o que é válido para essa objetividade em geral deve agora ser válido a todo objeto pertencente a essa estrutura do ser [Seinsstruktur]. A novidade nesse giro [Wendung] parece-me estar no fato de que agora não existe mais uma única estrutura do ser, mas, pelo contrário, temos estruturas completamente diferentes. Toda nova estrutura do ser tem suas novas pressuposições a priori. Kant mostra que tal estrutura está ligada às condições de possibilidade da experiência, mostra como toda nova espécie de forma também se refere 
agora a um novo mundo objetivo, como o objeto estético não é ligado ao objeto empírico, como ele tem suas categorias a priori, como a arte também constrói um universo, como, porém, essas leis são diferentes das leis do físico. Por essa razão, uma multiplicidade completamente nova toca o problema do objeto em geral. E por essa razão, a nova metafísica kantiana forma-se precisamente da metafísica antiga e dogmática. O ser [Das Sein] da antiga metafísica era a substância, o que forma um fundamento. O ser na nova metafísica é, na minha linguagem, não mais o ser da substância, mas o ser que parte de uma variedade de determinações funcionais e de significados. $\mathrm{O}$ ponto essencial que distingue minha posição da de Heidegger parece, a mim, estar aqui.

Eu permaneço junto à posição do questionamento kantiano do transcendental, como Cohen repetidamente [immer wieder] o formulou. Cohen via nisso a essencialidade do método transcendental, que esse método começa com um fato [Faktum]; só ele possuía essa definição geral: começar com um fato, a fim de questionar a possibilidade desse fato, novamente restringindo-o [295] na medida em que ele sempre apresentava novamente, como algo propriamente questionável, a ciência natural matemática. Kant não permanece nessa restrição. Porém, eu pergunto pela possibilidade do fato da linguagem. Como pode ser, como é pensável que nós possamos nos entender, nesse meio, de ser-aí para ser-aí [von Dasein zu Dasein]? Como é possível que nós possamos realmente ver uma obra de arte como algo passível de determinação objetiva, enquanto ente objetivo, como algo pleno de sentido em sua totalidade?

Essa questão precisa ser resolvida. Talvez, a partir daqui, nem todas as questões da filosofia possam ser resolvidas. Quem sabe não se possa prosseguir adiante em tais vastos domínios. Porém, é necessário que, antes de mais nada, se coloque essa questão. E eu creio que, apenas quando essa questão for colocada, será liberado o acesso ao questionamento [Fragestellung] de Heidegger.

Heidegger: A última questão de Cassirer, no confronto de Kant com a antiguidade, dá a mim novamente a oportunidade de caracterizar a obra integral. Eu digo que a pergunta de Platão deve ser retomada. Isso não quer dizer que devemos retornar à resposta dos gregos. Torna-se evidente que o próprio ser [Sein] está fragmentado em uma multiplicidade, e que nisso perdura um problema central, conquistar o solo a fim de que se compreenda a multiplicidade interna dos modos de ser [Sein] a partir da ideia de ser. E eu tenho me empenhado em extrair esse sentido de ser em geral como algo central. E o único esforço 
de minhas investigações está dirigido a obter o horizonte para a questão do ser, sua estrutura e sua multiplicidade.

A mera mediação nunca será produtiva para avançar. É a essência da filosofia enquanto questão [Angelegenheit] finita do ser humano, que ela esteja restrita à finitude do ser humano, tal qual nenhuma outra realização criativa do ser humano. Porque a Filosofia perpassa a totalidade e o mais elevado ser humano, [296] a finitude deve se mostrar de modo totalmente radical na Filosofia. É importante que os senhores levem convosco uma única coisa dessa nossa confrontação: não se orientem pela diversidade de posições dos seres humanos filosofantes, e que os senhores não devem se ocupar com Cassirer e com Heidegger, mas devem chegar ao ponto de pressentir que nós estamos a caminho de tomar seriamente mais uma vez a questão central da metafísica. Gostaria de indicar aos senhores o fato de que aquilo que os senhores estão vendo aqui em pequena medida, a diferença dos filósofos na unidade da problemática, pode se expressar de maneira totalmente diversa em um âmbito maior. $\mathrm{O}$ essencial na confrontação com a história da filosofia é precisamente o fato de ser o passo inicial para o interior da história da filosofia o libertar-se da diferença entre as posições e os pontos de vista; ver como justamente a distinção de pontos de vista é a raiz do trabalho filosófico.

\section{Referência bibliográfica}

HEIDEGGER, M. Gesamtausgabe Band III - Kant und das Problem der Metaphysik. Anhang IV, pp.274-296, Ed. Vittorio Klostermann, Frankfurt am Main, 1991.

Recebido em: 10/04/2020 | Aprovado em: 15/06/2020 